\title{
Art Installation as a Catalyst to Activities and Positive Behaviour in Back Lanes of Shah Alam Commercial Areas
}

\author{
Nurulhusna Qamaruz Zaman *, Aidatul Fadzlin Bakri, Sabarinah Sheikh Ahmad, Ahmad Tarmizi Ab Jalal \\ Center of Studies for Architecture, Faculty of Architecture, Planning and Surveying, Universiti Teknologi MARA, \\ 40450 Shah Alam, Selangor, Malaysia.
}

\begin{abstract}
This paper represents on women behavior safety enigma, also an on-going progress study of the cultural landscape in the context of the historic city where knowledge unfolds. The study has tracked women's experience of place, which responses on the visual elements that become an incredibly diverse culture surrounding and norms. Eventually, the historic city seems meet their expectations in cultural aspects a safe building has resulted for living and work environment. Therefore, having known their understanding influence on structure-building façade concluded and rediscovered the perception that adds value contributes in the urban setting.

(C) 2016. The Authors. Published for AMER ABRA by e-International Publishing House, Ltd., UK. Peer-review under responsibility of AMER (Association of Malaysian Environment-Behaviour Researchers), ABRA (Association of Behavioural Researchers on Asians) and cE-Bs (Centre for Environment-Behaviour Studies, Faculty of Architecture, Planning \& Surveying, Universiti Teknologi MARA, Malaysia.
\end{abstract}

Keywords: People and environments; cultural knowledge; architecture; indigenous architecture

\section{Introduction}

The community involvement in the planning of urban public spaces is a raising practice nowadays to gain crucial input from the public regarding their needs and preferences for the spaces that they live in. Widodo (2012) advocates that a building process is a community event and effort, hence requires the architect to immerse himself completely in the community and the transformation process. It is a materialization of culture that continuously transformed and enriched over the period of time and a process of physical-spatial articulation of social-cultural inhabitation. Merely depending on the designers to produce a good public space based on higher level decisionmaking without co-operation of the public, might not be as successful in improving social life that enhance the social interactions between the urban communities, (Wan Ismail W.A., et all, 2015).

According to Shamsuddin, S. et all (2013), the urban form that encourage walkability is the current trend for city design where human scale activities are encouraged at the street level to attract people to walk in the city centres. Well managed streetscapes furniture with strong character is essential for producing a comfortable and conducive environment for walking that could improve the biological health of the pedestrians. However, disconnected streets that are often gloomy, scary and unnoticed such as the back alley becomes a hindrance to walkability. The unnoticed back alley that is usually underutilized is also categorized as spaces of uncertainty.

\footnotetext{
* Corresponding author. Tel.:

E-mail address: nhusnaqz@yahoo.com
}

(C) 2016. The Authors. Published for AMER ABRA by e-International Publishing House, Ltd., UK. Peer-review under responsibility of AMER (Association of Malaysian Environment-Behaviour Researchers), ABRA (Association of Behavioural Researchers on Asians) and cE-Bs (Centre for EnvironmentBehaviour Studies, Faculty of Architecture, Planning \& Surveying, Universiti Teknologi MARA, Malaysia.

DOI: http://dx.doi.org/10.21834/e-bpj.v111.230 
In the spaces of uncertainty, resultant behavior could be positive or negative based on the utilization of space by the people. This differs to the designed public spaces where people react to programmed activities and its setting based on the perceived environmental constraint. Negative utilization of the spaces of uncertainty might attract criminals whilst positive utilization of spaces of uncertainty could grow a strong self-reliance community with a strong identity and contributes to the city's vibrancy and safety. Human behavior in design spaces might differ in spaces of uncertainty. The ambiance of public spaces either designed or unplanned affects the behavior and experience of people. According the Aghostin-Sanggar V.(2007), human behavior, experiences and social interactions in public spaces are the results of the mind processes influenced by different features that maybe physical, social, cultural or sensory.

In spaces of uncertainty where the spaces are mostly unnoticed and partially a no man's land, profit making is not the primary, thus budget and time are not so much a constraint, but yet some of these spaces are utilized by its community despite lack of designers touch. This suggests that there is a gap in the human behavior theory specifically in the areas of spaces of uncertainty where opportunities for exploration of activities by its immediate communities. This research aims to identify further spaces of uncertainty utilization and formulate a new theory of human behavior in spaces of uncertainty to foster a safe and peaceful develop nation. This is in line with the National Key Results Area (NKRA) 1 that is to reduce crime and Chapter 6 of the 10th Malaysia Plan.

\section{Literature Review}

Issues' relating to the spaces of uncertainty in Malaysia centers upon the utilization of these spaces whether it is utilized positively or negatively and how it affects neighbouring communities. Publicly owned spaces of uncertainty where restraints are vague, an opportunity for intervention and explorations of uses by the community become broad (Qamaruz Zaman, N. et all, 2013). Spaces of uncertainty is defined as leftover spaces by Muller and Busmann (2012), underutilized old buildings yards, lanes, or casual passageways by Akkerman and Ariela F. Cornfeld (2009), unnoticed and meaningless urban voids by Eli First and Tamar Pertzov (2004). In these spaces, regulations and surveillance are lacking, hence causes the feeling of unsafe and fear of crime. Back alley is used as a passage for services behind a building, an alternative that is commonly abandoned, excluded and becomes a crime prone area. In Malaysia, back alleys tend to be a long and excluded terrace.

The installation of art in the back alley could change the negative perception of back alleys. Arts is a universally accepted medium that could transform gloomy back alleys into a more lively and comfortable area. According to Seymour, W. et all (2010), adding cultural and inspirational murals, allowing graffiti artists to decorate the alley for aesthetic purposes, adding trees, grass, and benches could make back alley a more pleasant space for people. Back alley could be turned into a tolerable space for the community that prevents crime and at the same time improve the urban condition and enhance safety. Interpretations of public art in public spaces can be subjective. The ideas and values created by the artists could be responsive to the place, its community, its people, the politics, and the social or environmental issue that could be digested by the public. Apart from reflecting the values of society and transform a landscape, public art is also a medium used to deliver messages and indirect education. It is an expression of how the artists want the community to see and response to the time and place based on individual interpretations.

\subsection{Public art impact to the community}

Public art can give value to a city, to its society, to the culture and the local economy. It engraves the evolving culture that advocates scenario of the society at a particular location, crossing between the past, present and future, between movements, and between ideas. Public art could enhance the built environment and rejuvenate public spaces, accessible to all walks of life at any time of the day, and it is usually without a cost. A recent study on the influence of art installation in public space has shown that the art installation is a catalyst, opening a metaphorical conversation about the role of art in contemporary society (Grigoleit, A., 2013). Art has its own power, power of attraction and influence, which can provide a positive ambiance that attracts the crowd and generate the positive behaviour of the visitors. Ziarek (2002) stated that art can take over the relations between forces in society and transposes them into its own aesthetic force.

\subsection{Public Art impact to social, culture and economy}

Participation in the arts improves physical and psychological well-being (Joshua Guetzkow, 2002), enhance individual life through encouraging individual creativity, spirit, and potential through providing release, relaxation, and entertainment (Arthurs, 
1998). Public art space could also become a venue that draws people together who would otherwise not be engaged in a constructive social activity. An art process that involves professional artists and community members in a collaborative creative process produces collective experience and public expression (Guetzkow, 2002). Art could also build social capital by getting people involved, by connecting organizations to each other and by giving participants experience in organizing and working with local government and non-profits (Guetzkow, 2002). Public art can build community identity and pride, leading to positive community norms, such as diversity, tolerance and free expression (Guetzkow, 2002). Amongst other benefits of installing public arts includes the opportunity for business and commercial activities due to the crowd hauled by it. "My murals help the city look better, brighter, improve business and property values". (Mike, 2009). Guetzkow (2002) revealed that public art space increases the attractiveness of an area to tourists, businesses, people and investment.

\subsection{Types of art installation}

There are various types of public art installation that includes (but not limited to) $2 \mathrm{~d}$ painting, $3 \mathrm{~d}$ painting, $3 \mathrm{~d}$ installation and street furniture. $2 \mathrm{~d}$ painting is an art on a flat surface, created by the artist on the wall or the ground that is also known as mural art or graffiti. The media used could be paint or spray. $3 \mathrm{~d}$ painting is a perspective on a tonal drawing that creates $3 \mathrm{~d}$ effect when the user stands at a specific point. $3 \mathrm{~d}$ installation is an art of $3 \mathrm{~d}$ objects that could also be defined as sculpture or mixed art. Street furniture is objects placed permanently or temporarily in public spaces that create attractiveness, and it is a meaningful aspect of the urban public open space. Jane Jacob (1961), an urban planning guru mentioned that 'if the city's street looks interesting, the city looks interesting, if they look dull, the city looks dull'. According to Bulut \& Atabeyo (2006) from Aziz, A. et all (2012), street are not merely created to accommodate traffic, but it also adds meaning to the city identities and uplift the life of the society through its design, quality, function and aesthetic value.

\section{Research Methodology}

Fundamentally, both qualitative and quantitative methods are adopted in doing this research that includes questionnaire survey, data tabulation using the SPSS software and field observation. Field observation was done in both case studies focussing on the user's behaviour, the condition of space and the activities that occurred in Laman Seni 2 and Laman Seni 7. Data are recorded via photography and notes on human behaviour. The questionnaire survey was designed to get information on user's appreciation, experience and feelings with regards to the art installation at the back alley. The questionnaire was distributed in the site study in the back alley of commercial centre Section 7, Shah Alam, also known as Laman Seni 7.The questionnaire survey was done in the morning, afternoon and evening within four days in which two days on weekdays and the other two days was on a weekend. The survey was done in the month of October 2014 using a random sampling technique. Data collected from the questionnaire survey was tabulated using SPSS software with the number of 40 respondents. Next, the data was used to determine the relationship between public art installation and the effects towards the user's behaviour. It analyses the current condition and quality of space of the back alley that has transformed into a public place.

\section{Findings}

Based on the site observation done on both case studies that is Laman Seni 2 and Laman Seni 7, new activities seemed to materialize to an otherwise a lifeless, unnoticed and scary back lane. Various types of art installations succeeded in producing a positive urban space that attracts the public to visit the back lanes for various reasons and activities, turning the back lane into an active, vibrant and enjoyable space. The space is more than a hub for the artist to express their talents; it is the place for art lovers and local people meet and interact. The back lane has turned into a phenomenal scene where it becomes a new leisure ground that is suitable for all ages, creates an opportunity for networking as well as a business opportunity that promotes better and healthy urban lifestyle.

\subsection{The case studies: Laman Seni 2 and Laman Seni 7 in Shah Alam}

The case studies for this research are located in Shah Alam commercial areas that are in Section 2 and Section 7. The project of the art installation was managed by the KHZNH Studio with the consent of the local authority, MBSA (Majlis Bandaraya 
Shah Alam). Laman Seni 2 was a pioneer street art project before Laman Seni 7 street art competition was undertaken. The successfulness of Laman Seni 2 to 'redefine the back lanes into a usable space for the community' (KHZNH, 2015), brought to an experimentation of street art competition of Laman Seni 7 which as anticipated produced a wider attraction due to publicity, promotions and participation of all walks of life. Continuous updates via Facebook of KHZNH and individual artists create awareness to the public and the excitement to see its completion.

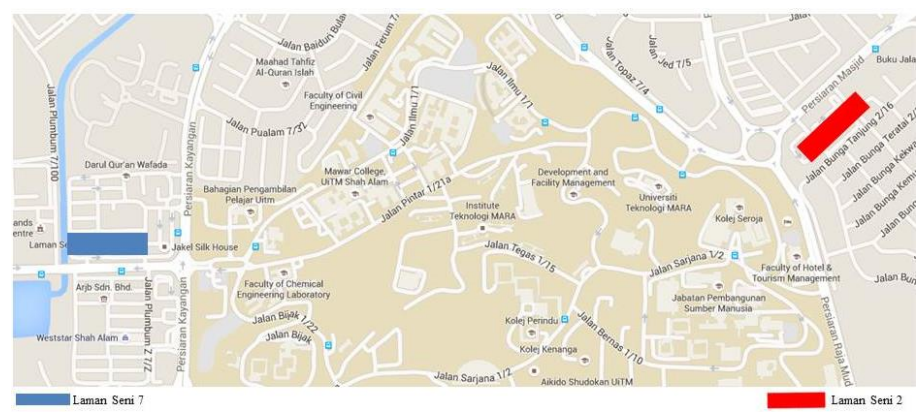

Figure 1: Location of the case studies, Laman Seni 2 and Laman Seni 7

(Source: Google map)

\subsection{Behaviour and Activities in Laman Seni 2}

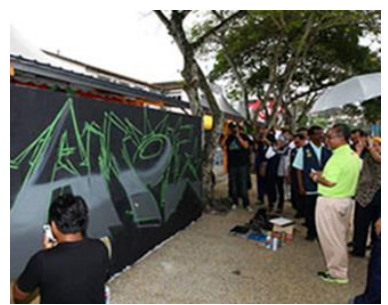

(a)

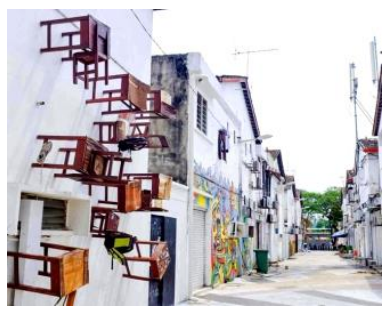

(c)

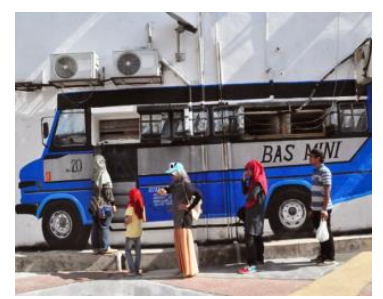

(b)

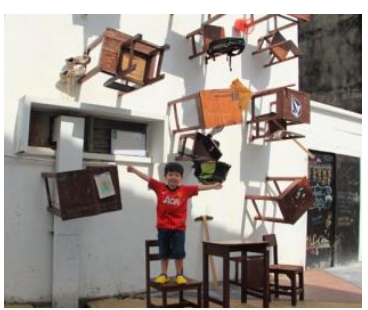

(d) 


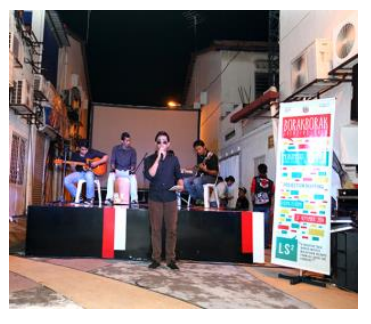

(e)

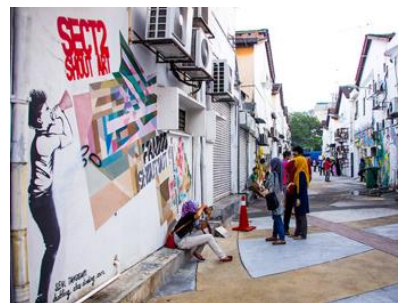

(f)

Figure 2: (a) Art installation in Laman Seni 2after completion, (b) Crowd hanging out and appreciating the artwork, (c) Children relates well to the 'outdoor classroom' 3d installation, (d) Mural painting, (e) Versatility of photo taking, (f) Music band performance.

(Source: Tarmizi, 2014)

\subsection{Behaviour and activities in Laman Seni 7}

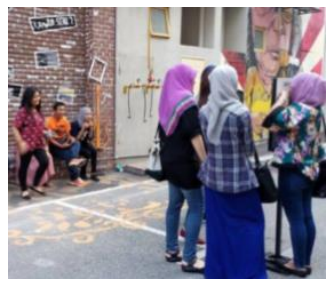

(a)

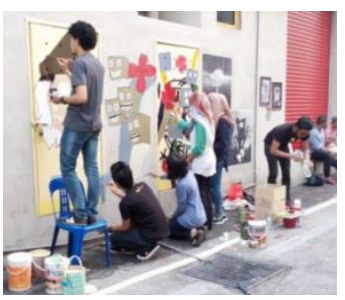

(c)

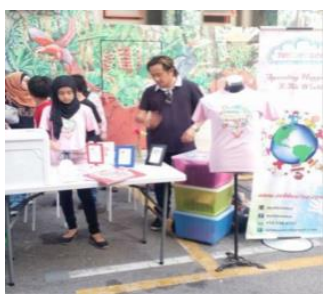

(e)

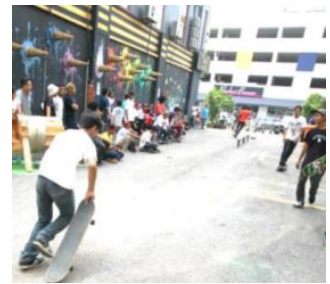

(b)

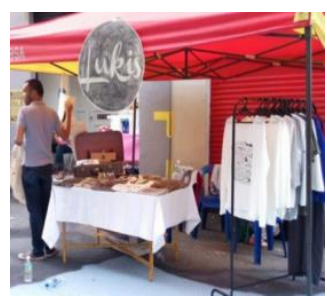

(d)

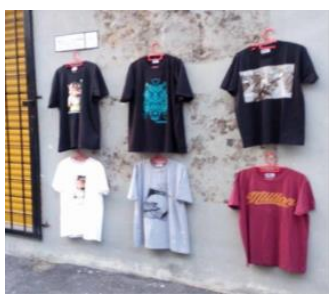

(f) 


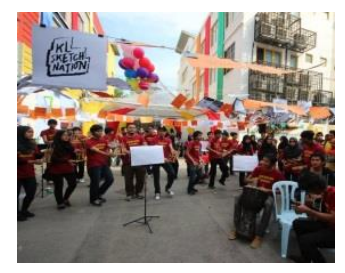

(g)

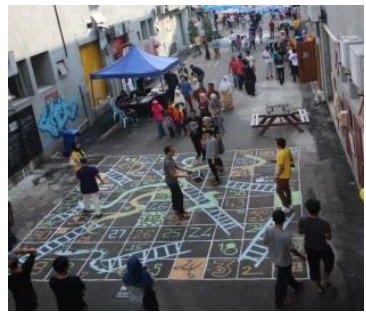

(i)

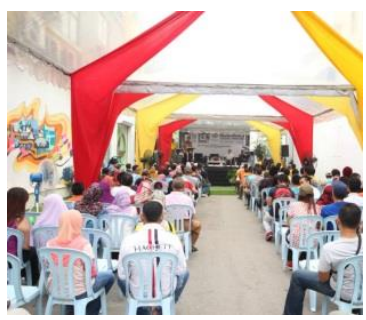

(k)

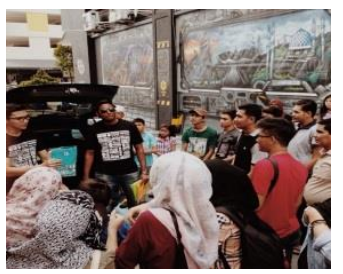

(h)

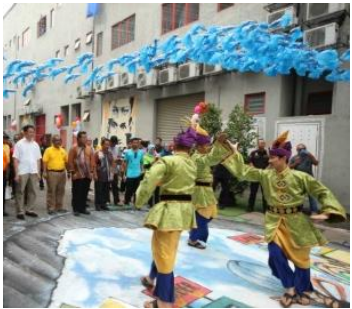

(j)

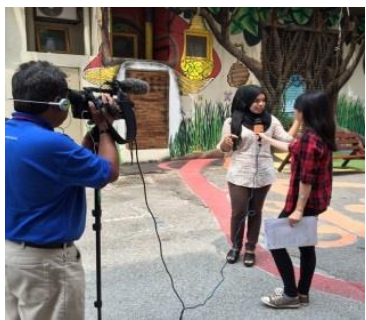

(I)

Figure 3: (a) Photo taking, (b) Skateboarding activity, (c) Mural painting, (d,e,f) Commercial activities or street bazaar (Source: Tarmizi,2014). (g) Mestika angklung performance, (h) Radio Station Crew, (i) Recreational activities, (j) Cultural performance, (k) Opening ceremony, (I) TV coverage.

(Source: KHZNH studio)

\subsection{Activity updates and publicity}

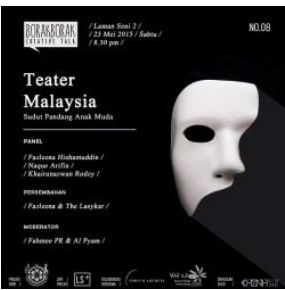

(a)

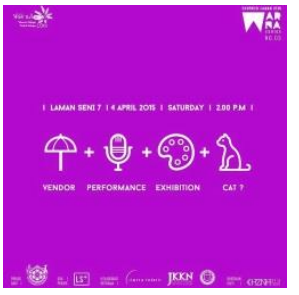

(b)

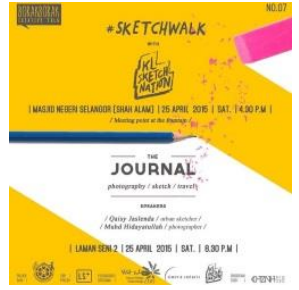

(c)

Figure 4: $(a, b, c)$ The activates and programs that are to be held at both Laman Seni 2 and Laman Seni 7 are make known to the public through banners, fliers and social media such as Facebook. Cotinous updates could be accessible successfully through KHZNH Studio Facebook and the MBSA Digital Screen 


\subsection{Questionnaire survey analysis}

A simple and questionnaire survey was distributed in Laman Seri 7 with the purpose of getting the idea on the people that uses Laman Seni 7, their purpose of visits, their preferences on the and the influence of the installed arts to the user's feelings.

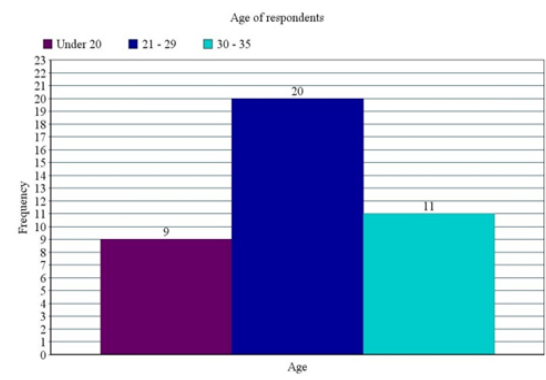

(a)

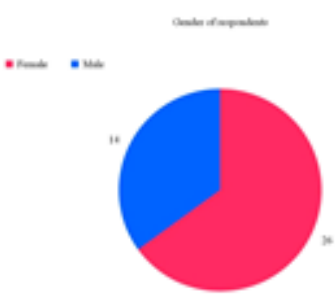

(b)

Figure 5: (a) Among the respondents, female are more than the male users with (b) the age group of 21-29 is higher than the under 20 years of age and $30-35$ age group

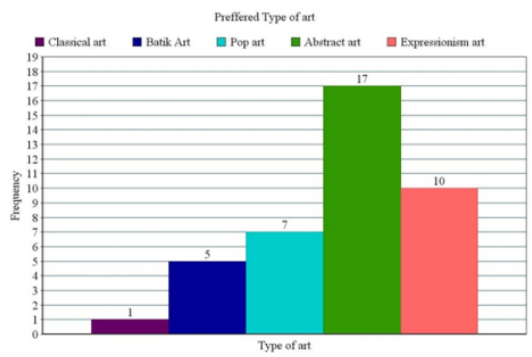

(a)

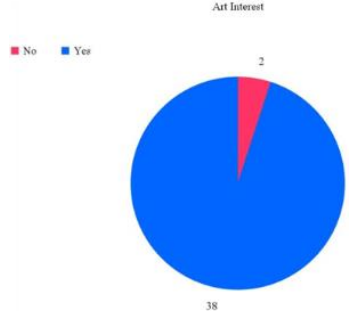

(b)

Figure 6: (a) The respondents that are interested in arts are higher in number than those without arts interest, (b) the preferences of the types of arts are highest in the abstract arts, followed by expressionism, pop art, batik art and the least preferred in the classical arts

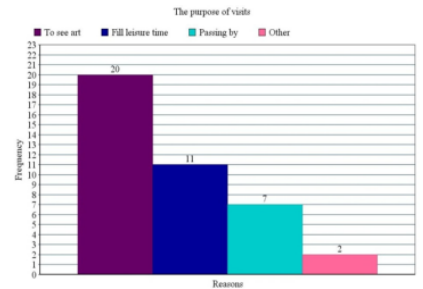

(a)

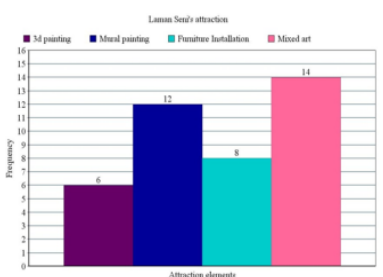

(b)

Figure 7: (a) The purpose of visits of the respondents are highest at wanting to view the art piece as compared to filling the leisure time and passing by, (b) Mixed art is seemed to be the attraction of Laman Seni 7, followed by mural painting, furniture installation and lastly 3D painting 


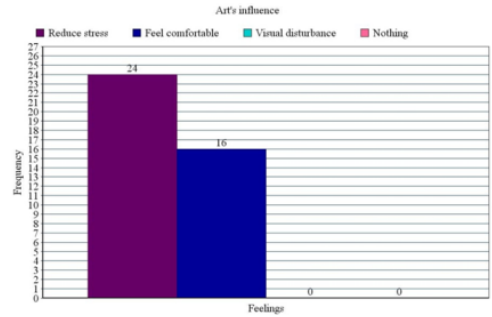

(a)

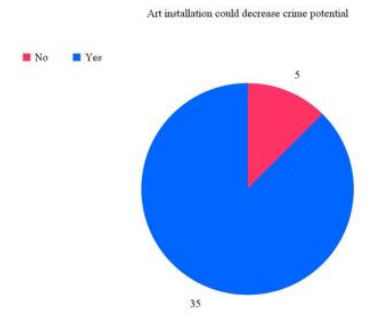

(b)

Figure 8: (a) Most respondents feels that they could reduce their stress when visiting Laman Seni 7 and some feels comfortable. None of the respondents feels that the art installation is a visual disturbance, (b) Most respondents feels that the art installation could reduce the crime potentials

\section{Conclusion}

The installation of art in public space gives a positive impact on the environment of a back lane socially, culturally and economically. Transformation of the back lanes into attractive, lively and vibrant part of the city attracts the crowd of inhabitants to appreciate the art installation, cultivating various activities and positive behavior. The once 'spaces of uncertainty' now becomes a destination where various layers of community intermingle. Based on the survey, a majority of the respondent's feels comfortable, calm and feels that they could reduce their stress when they visit Laman Seni 7. The back alley transformations reduce the feeling of unsafe and fear of crime because the back lane is no longer a secluded place in the urban framework. Human scale activities such as recreational activities, street performances, and commercial activities increase the probability of walkability, hence promoting a healthy living environment in the city.

It could also be concluded that art installation is a catalyst towards positive behavior and lively activities. However, the type of art installation that is of preferences is the mixed art as compared to merely 3D paintings. This is an important finding as it gives significant information on the things that could attract the public. Mixed art opens up for the possibility of uses and behaviors, allowing the users to explore further the art piece.

Apart from the art installation, continuity of events and activities is crucial to ensure that the users keep on coming to the venue and not just a 'one time visit'. A Variety of events should be formulated to attract various layers of the community to use the public space. Effective ways of informing the public about the events that will be held at the venue are also crucial to ensure for the successfulness of the events.

The most crucial aspect of the back alley transformation is promotions of the effort, community involvement since the beginning of the project to instill the sense of belonging to the space, once it is transformed. It is the process from the start to the end that gives meanings to the users, making them comfortable to explore and adopt to the space rather than the rigidness of the completed product or projects. Collaboration with the local council and the public participations could be more successful in creating a good public space as compared to the decision making by a single party alone.

\section{Recommendations}

It is highly recommended that place-keeping could be practiced to ensure that the condition of the paintings on the back alley is always in good condition. Collaborative maintenance activities should be formulated to increase the sense of belonging to the community rather than depending solely on the local authorities to maintain the space. Periodical art competition could also be done at the same venue in order to give new attraction after some time in order to recreate the excitement. The quality of lighting in the Laman Seni during night time should be enhanced to ensure comfort and safety. Installation of lamp art to illuminate the area could both illuminate the area and enhances the art installations project. Green elements to soften and balance the hardscape features in the form of greenscape could increase the richness of the venue, making it more interesting and energized. Cafes or food vendor could also excite the venue and ensure continuous 'eyes on the street'. 


\section{Acknowledgement}

The authors would like to acknowledge Universiti Teknologi MARA and the Ministry of Higher Education for the funding of the research project via RAGS grant 600-RMI/RAGS 5/3 (170/2013). Highest appreciation to all parties that were involved in the research activities from the beginning to its completion. The respondents that have given useful feedbacks, the users that have honestly given their feedback through their behavior in the Laman Seni 2 and Laman Seni 7 and last but not the least to KHNZH studio and MBSA for their continuous effort at transforming the back lanes in Shah Alam into a public place for the benefit of the community.

\section{References}

Arnis Aziz1, Osman Mohd Tahir2, and Mohamad Fakri Zaky Ja'afar3(2012). Significances Of Sustainability Street Furniture Design In Malaysia. Proceedings of the 2nd. International Conference on Arts, Social Sciences Technology Penang, Malaysia, 3rd. - 5th.March 2012. Paper Code. No. I2112.

Grigoleit, A., Hahn, J., \& Brocchi, D. (2013). "And in the end my street will not be the same". The art project 2-3 Streets and its link to (un)sustainability, creative urban development and modernization. City, Culture and Society, 4(3), 173-185. doi:10.1016/j.ccs.2013.05.002.

Qamaruz-Zaman N., Samadi S., Nik Azhari N.F. (2013) Under The Flyovers of Kuala Lumpur: User Centered Activities in Leftover Spaces. Journal of Asian Behavioural Studies, Volume 3, Number 10, $89-103$.

Seymour, M., Wolch, J., Reynolds, K. D., \& Bradbury, H. (2010). Resident perceptions of urban alleys and alley greening. Applied Geography, 30(3), 380-393. doi:10.1016/j.apgeog.2009.11.002.

Shamsuddin S., Abu Hassan N.R., Bilyamin S.F.I. (2013). Walkable in Order to be Livable. Journal of Asian Behavioural Studies, Volume 3, Number 11, 111 121.

Venetin Aghostin-Sangar (2007), Human Behaviour In Public Spaces. A thesis submitted to the Faculty of Built Environment, University of New South Wales Wan Ismail W.A., Said I. (2015). Integrating the Community in Urban Design and Planning of Public Spaces: A review in Malaysian Cities. Procedia - Social and Behavioral Sciences, 168, $357-364$.

Widodo J. (2012). Urban Environment and Human Behaviour: Learning from History and Local Wisdom. Procedia - Social and Behavioral Sciences 42 ( 2012 ) 6 $-11$.

Ziarek, K. (2002). The turn of art: The avant-garde and power. The Turn of Art: The Avant-Garde and Power, 33(1), 89-107,190. 